\title{
Effects of Citrin Deficiency in the Perinatal Period: Feasibility of Newborn Mass Screening for Citrin Deficiency
}

\author{
AKIKO TAMAMORI, AKIE FUJIMOTO, YOSHIYUKI OKANO, KEIKO KOBAYASHI, \\ TAKEYORI SAHEKI, YASUKO TAGAMI, HAZIME TAKEI, YOSUKE SHIGEMATSU, IKUE HATA, \\ HAJIME OZAKI, DAISUKE TOKUHARA, YUTAKA NISHIMURA, TOHRU YORIFUJI, \\ NOBORU IGARASHI, TOSHIHIRO OHURA, TAKASHI SHIMIZU, KOJI INUI, NORIO SAKAI, \\ DAIKI ABUKAWA, TAKAYUKI MIYAKAWA, MIKA MATSUMORI, KYOKO BAN, \\ HIROAKI KANEKO, AND TSUNEKAZU YAMANO \\ Department of Pediatrics [A.T., Y.O., D.T., T.Ya.], Osaka City University Graduate School of Medicine, Osaka \\ 545-8585, Japan; Osaka City Environment and Public Health Association [A.F.], Osaka 541-0055, Japan; \\ Department of Molecular Metabolism and Biochemical Genetics [K.K., T.Sa.], Kagoshima University Graduate \\ School of Medical and Dental Sciences, Kagoshima 890-8520, Japan; Sapporo City Institute of Public Health [Y.T.], \\ Sapporo 003-8505, Japan; Tokyo Health Service Association [H.T.], Tokyo 162-0842, Japan, Department of \\ Pediatrics [Y.S., I.H.], Fukui Medical University School of Medicine, Fukui 910-1193, Japan; Yodogawa Ward \\ Public Health and Welfare Center [H.O.], Osaka 532-0023, Japan, Department of Pediatrics [Y.N.], Hiroshima \\ University Graduate School of Biomedical Sciences, Hiroshima 734-8551, Japan [Y.N.], Department of Pediatrics \\ [T.Yo.], Kyoto University Hospital, Kyoto 606-8507, Japan; Department of Pediatrics [N.I.], Toyama Prefectural \\ Central Hospital, Toyama 930-8550, Japan, Department of Pediatrics [T.O.], Tohoku University School of Medicine, \\ Sendai 980-8575, Japan; Department of Pediatrics [T.Sh.], National Ureshino Hospital, Ureshino 843-0393, Japan, \\ Department of Developmental Medicine (Pediatrics) [K.I., N.S.], Osaka University Graduate School of Medicine, \\ Suita 565-0871, Japan; Miyagi Children's Hospital [D.A], Sendai 980-0873, Japan; Department of Pediatrics \\ [T.M.], School of Medicine, University of Occupational and Environmental Health, Kitakyusyu 807-8555, Japan; \\ Department of Pediatrics [M.M.], Akita University School of Medicine, Akita 010-8543, Japan; Department of \\ Pediatrics [K.B.], Neonatology and Congenital Disorders, Nagoya City University Graduate School of Medical \\ Sciences, Nagoya 467-8602, Japan; and Department of Pediatrics and Developmental Medicine [H.K.], Gunma \\ University Graduate School of Medicine, Maebashi 371-8511, Japan
}

\section{ABSTRACT}

Deficiency of citrin due to mutations of the SLC25A13 gene causes adult-onset type II citrullinemia (CTLN2) and one type of neonatal intrahepatic cholestasis (NICCD). About half of the NICCD patients are detected based on high galactose, phenylalanine, and/or methionine concentrations on newborn mass screening (NMS). To clarify the perinatal and neonatal effects and the inconsistent results on NMS, we examined aminograms, the levels of bile acids and galactose in dried blood spots for NMS from 20 patients with NICCD. Birth weight was low for gestational age $(-1.4 \pm 0.7$ $\mathrm{SD})$. Affected fetuses may have suffered intrauterine citrin deficiency. The first abnormality detected after birth was citrullinemia, and 19 of 20 patients had citrulline levels higher than +2 SD of controls. Tyrosine, phenylalanine, methionine, galactose, and bile acids were less affected than citrulline on d 5 after birth. Galactose and bile acids levels were increased at 1 mo in comparison with $d$ 5 after birth due to impairment of the cytosolic NADH reducingequivalent supply into mitochondria of hepatocytes. Patients with negative findings on NMS had low levels of total 20 amino acids. Citrulline/serine, citrulline /leucine plus isoleucine, and citrulline/ total amino acids ratios, controlled for the confounding effect of low amount of total amino acids, were higher in all patients than $+2 \mathrm{SD}$, $+2 \mathrm{SD}$, and $+3 \mathrm{SD}$ of controls, respectively. NMS for citrin deficiency (frequency of homozygote with SLC25A13 mutation: $1 / 10,000-1 / 38,000$ in East Asia) will be useful for clarification of the clinical course, treatment, and prevention of this disease. (Pediatr Res 56: 608-614, 2004)
CTLN2, adult-onset type II citrullinemia
NICCD, neonatal intrahepatic cholestasis caused by citrin deficiency
NMS, newborn mass screening

CTLN2 (OMIM \#603471) is characterized by late onset (age, 11-79 y), frequent attacks of hyperammonemia, mental

Received October 7, 2003; accepted April 6, 2004.

Correspondence: Yoshiyuki Okano, M.D., Department of Pediatrics, Osaka City University Graduate School of Medicine, 1-4-3 Asahimachi, Abeno-ku, Osaka 545-8585, Japan; e-mail: okano@med.osaka-cu.ac.jp

Supported by grants from the Ministry of Health Sciences and Welfare of Japan, by a Grant-in-Aid for Scientific Research from the Japan Society for the Promotion of Science, derangement, sudden attacks of unconsciousness, and ultimately death within a few years of onset $(1,2)$. CTLN2 is caused by mutations of the SLC25A13 gene (3-5), which is localized on chromosome 7q21.3 and encodes a calcium-

and by funds from Suyama Research Foundation.

DOI: 10.1203/01.PDR.0000139713.64264.BC 
binding mitochondrial protein, designated citrin (3). Citrin, an aspartate glutamate carrier, plays an important role in the malate-aspartate NADH shuttle and urea synthesis $(6,7)$. Impairment of citrin function can lead to increased NADH/NAD ${ }^{+}$ ratio in the cytosol and failure of aspartate supply from the mitochondria to the cytoplasm for synthesis of argininosuccinate, resulting in high blood levels of citrulline and ammonia. Infants carrying mutations in the SLC25A13 gene exhibit cholestatic jaundice in the neonatal period (8-10), and can later show the aforementioned symptoms of CTLN2 $(7,10)$. In Japan, more than 100 neonates or infants suffering from this particular type of neonatal hepatitis were found to carry mutations in the SLC25A13 gene (5,7-14), and have been designated NICCD (OMIM \#605814) $(5,8)$. They suffer a variety of transient symptoms of cholestasis, hypercitrullinemia, hypertyrosinemia, hypergalactosemia, hypoproteinemia, and hypoglycemia due to liver dysfunction caused by citrin deficiency. The condition is often self-limiting after maturation of hepatocytes and/or adaptation or compensation by other mitochondrial carriers. However, some patients with this disorder exhibit severe hepatic dysfunction requiring liver transplantation $(7,12)$. CTLN2 and NICCD appear to be almost exclusively found in Japan. However, three Chinese CTLN2 patients from Taiwan and Beijing and a Vietnamese infant suffering from NICCD in Australia have recently been reported $(14,15)$. Interestingly, they all had the same SLC25A13 mutations as those identified in Japanese patients. Preliminary population analysis of the known nine SLC25A13 mutations revealed that the carrier frequency is high $(1 / 50-1 / 98)$ in China, Taiwan, and Korea as well as in Japan (14), indicating that citrin deficiency may be present throughout East Asian populations. About half of the Japanese patients with NICCD were identified on NMS based on the presence of hypergalactosemia, hyperphenylalaninemia, and/or hypermethioninemia, whereas the other half was identified after the appearance of jaundice and/or failure to thrive (13). To clarify the perinatal and neonatal features and to investigate the differences between positive and negative findings on NMS, we measured 20 amino acids, bile acids, and galactose in dried blood spots from the NMS samples of 20 patients with NICCD. We also report here the possibility of using NMS to detect NICCD.

\section{PATIENTS AND METHODS}

Patients. Twenty patients (11 males, 9 females) with neonatal intrahepatic cholestasis at participating institutions were confirmed to have citrin deficiency by genetic analysis, as shown in Table 1. The 18 unrelated and 2 related patients had healthy parents. NMS was positive in nine infants as follows: high galactose $(n=2)$, high phenylalanine $(n=2)$, high galactose and phenylalanine $(n=3)$, and high galactose and methionine $(n=2)$. The other 11 patients were referred to the hospital for jaundice, failure to thrive, and/or acholic stool and were suspected to have citrin deficiency after excluding infectious hepatitis, metabolic disease, and biliary tract disease. The patients, weighing from 1976 to $3144 \mathrm{~g}$ at birth, were born at $36-41 \mathrm{wk}$ of gestation. The birth weight was $-1.4 \mathrm{SD} \pm 0.7$ (range, -2.1 to $-0.1 \mathrm{SD}$ ), as shown in Table 1. All patients were below the average birth weight, which took into account the gestational age, sex, and first childbirth. There was no significant difference in birth weight $(p=0.65)$ between NICCD patients who were positive and negative for phenylalanine, methionine, and/or galactose on NMS. Eight infants were fed breast milk, 2 were fed milk-based formulas, and 10 received both breast and formula milks. In 19 cases, the clinical and biochemical abnormalities improved by the age of $12 \mathrm{mo}$ without any specific treatment other than formulas containing medium-chain triglycerides, lactose-free formulas, and/or supplementation of fat-soluble vitamins $(12,13)$. However, one case, who was negative on NMS, developed severe hepatic dysfunction and required liver transplantation at the age of 10 mo (12).

Table 1. Perinatal history and mutations in 20 patients with NICCD

\begin{tabular}{|c|c|c|c|}
\hline & \multicolumn{3}{|c|}{ Newborn mass screening } \\
\hline & Positive & Negative & Total \\
\hline Number & 9 & 11 & 20 \\
\hline Gestational age (wk)* & $38 \pm 2.0$ & $39 \pm 1.0$ & $39 \pm 1.4$ \\
\hline Birth weight $(\mathrm{g})^{*}$ & $2377 \pm 237.6$ & $2534 \pm 386.7$ & $2467 \pm 333.4$ \\
\hline SD of birth weight* & $-1.5 \pm 0.46$ & $-1.3 \pm 0.87$ & $-1.4 \pm 0.70$ \\
\hline Formula & 2 & 0 & 2 \\
\hline Mix & 4 & 6 & 10 \\
\hline \multicolumn{4}{|l|}{ SLC25A13 mutation type } \\
\hline 851 del4/851del 4 & 1 & 2 & 3 \\
\hline 851del4/IVS11 $+1 \mathrm{G} \rightarrow \mathrm{A}$ & 4 & 1 & 5 \\
\hline 851del4/1638ins 23 & 0 & 1 & 1 \\
\hline $\mathrm{IVS} 13+1 \mathrm{G} \rightarrow \mathrm{A} / \mathrm{IVS} 13+1 \mathrm{G} \rightarrow \mathrm{A}$ & 0 & 1 & 1 \\
\hline
\end{tabular}

* Data are mean $\pm \mathrm{SD}$, others are number of patients. 
Amino acid analysis. Amino acid analysis from dried blood spots was performed using a HPLC system (Waters, Milford, MA) (16). A 1/8-inch blood disc was punched out into a well. To denature $\mathrm{Hb}, 10 \mu \mathrm{L}$ of organic solvent mixture (methanol, acetone, and water of 7:7:2) was added and dried at $37^{\circ} \mathrm{C}$ for $30 \mathrm{~min}$. Saline $(20 \mu \mathrm{L})$ with an internal standard of $\gamma$-aminobutylate $(5 \mu \mathrm{g} / \mathrm{mL})$ was added and vibrated for $10 \mathrm{~min}$ to extract amino acids. The sample was denatured with $90 \%$ ethanol $(80 \mu \mathrm{L})$ and centrifuged. Borate buffer $(70 \mu \mathrm{L})$ was added to the supernatant $(10 \mu \mathrm{L})$, and then it was derivatized with the AccQTag reagent kit (Waters) at $60^{\circ} \mathrm{C}$ for $10 \mathrm{~min}$ in a flat-bottom stripped microplate. After centrifugation, the supernatant was analyzed using the AccQTag HPLC system using a column oven kept at $40^{\circ} \mathrm{C}$. The original extract $(\mathrm{pH}$ 5.05) was used for general amino acid analysis, whereas the modified extract ( $\mathrm{pH}$ 5.60) was used for urea cycle amino acid analysis. We determined the control value of amino acids levels using 36 dried blood spots from subjects aged 4-6 d who were judged as normal on NMS.

Galactose. A 1/8-inch blood disc from a dried-blood newborn screening filter paper and $50 \mu \mathrm{L}$ of galactosemia test reagent (fluorescent test for GALT deficiency, supplied by F. Hoffmann-La Roche Ltd., Diagnostics Division, Basel, Switzerland) were placed in the well of a microplate. The plate stood for $1 \mathrm{~min}$ and then was centrifuged for $5 \mathrm{~min}$ at $2010 \times$ $g$. The plate was incubated for $1 \mathrm{~h}$ at $37^{\circ} \mathrm{C}$ for the enzyme reaction, and then shaken for $1 \mathrm{~min}$. Acetone-methanol mixture (100 $\mu \mathrm{L}$ of 1:1) was added to precipitate the $\mathrm{Hb}$ and protein. The plate was then centrifuged for $15 \mathrm{~min}$ at $2010 \times \mathrm{g}$. The supernatant $(35 \mu \mathrm{L})$ was added to a microstrip well (Thermo Electron Oy, Vantaa, Finland) containing $230 \mu \mathrm{L}$ of distilled water. The fluorescence intensity was measured at an emission wavelength of $360 \mathrm{~nm}$ (excitation wavelength, $450 \mathrm{~nm}$ ) using the MTP-100F fluorescent micro-plate reader (Corona Electric, Hitachinaka, Japan) $(17,18)$. We measured galactose-1phosphate and galactose levels in 2734 dried blood spots taken on routine NMS from newborns aged $4-6 \mathrm{~d}$ and determined the cut-off value $(0.39 \mathrm{mM}$, mean $+2 \mathrm{SD})$.

Bile acids. Bile acids (chenodeoxycholic acid and cholic acid) from dried blood spots were examined using an ELISA system. Blood discs (1/8 inch) from both patients and control were punched out into each well of an anti-rabbit IgG antibody-coated plate. Rabbit anti-chenodeoxycholic acid and anticholic acid anti-serum $(50 \mu \mathrm{L})$, and horseradish peroxidaselabeled chenodeoxycholic acid and cholic acid were added. After 10 min centrifugation and incubation for $18 \mathrm{~h}$ at room temperature, the blood discs and solution in each well were removed. The plate was then washed with $10 \mathrm{mM} \mathrm{Na}_{3} \mathrm{PO}_{4}$ buffer ( $\mathrm{pH} 7.2$ ) containing $0.1 \mathrm{M} \mathrm{NaCl}$, followed by the addition of $0.02 \%$ Tween 20 and $150 \mu \mathrm{L}$ color development solution $(0.1 \%$ orthophenylene diamine plus citric acid buffer, $\mathrm{pH}$ 4.5). The plate was incubated for $30 \mathrm{~min}$ at room temperature, and the absorbance was measured $492 \mathrm{~nm}$ after reaction with $100 \mu \mathrm{L}$ of $4 \mathrm{~N} \mathrm{H}_{2} \mathrm{SO}_{4}$. We determined the control value of bile acids using 80 dried blood spots taken on routine NMS from newborns aged 4-6 d.

DNA diagnosis of mutations. The nine mutations were detected by using the method established by Yamaguchi et al.
(5) as follows: the GeneScan (PerkinElmer Life and Analytical Sciences, Boston, MA) method was used for simultaneous detection of the deletion (851del4) and insertions (1638ins23 and 1800ins1). PCR was performed in a mixture containing fluorescent-labeled R110-dUTP, dNTP, and three sets of primers for mutations. After amplification for 35 cycles, the size of each R110-labeled PCR product was analyzed on an ABI-310 Genetic Analyzer (PerkinElmer Life and Analytical Sciences). The SNaPshot method was used for simultaneous detection of single base substitutions based on dideoxy single nucleotide extension of a labeled oligonucleotide primer. Two systems were provided: one for three mutations of IVS11 $+1 \mathrm{G} \rightarrow \mathrm{A}$, $\mathrm{S} 225 \mathrm{X}$, and IVS13 $+1 \mathrm{G} \rightarrow \mathrm{A}$, the other for three mutations of R605X, E601X, and E601 K. The first PCR was performed in a reaction mixture $(10 \mu \mathrm{L})$ containing primer sets, $0.2 \mathrm{mM}$ dNTP, and 0.2 units of TaqDNA polymerase. After amplification for 25 cycles, the mixture was treated with shrimp alkaline phosphatase and exonuclease I (USB Corporation, Cleveland, $\mathrm{OH}$ ) for $3-20 \mathrm{~h}$ at $37^{\circ} \mathrm{C}$, and then for $15 \mathrm{~min}$ at $72^{\circ} \mathrm{C}$ to inactivate the enzymes. The second PCR was performed with addition of annealing primers and a SNaPshot primer extension kit for 30 cycles, and then the mixture was treated with shrimp alkaline phosphatase. After heat treatment, the single extended fragments labeled by fluorescent dNTP were resolved on a genetic analyzer.

Informed consent for genetic analysis was obtained from all parents. Genetic analysis was authorized by the Medical Ethics Committee, Faculty of Medicine, Kagoshima University.

Data analysis. All data are expressed as mean \pm SD unless otherwise stated. Differences between groups were examined for statistical significance using the Mann-Whitney $U$ test. A $p$ value $<0.05$ denoted the presence of a statistically significant difference. Statistical analysis was performed using the StatView program version 4.5 (Abacus Concepts, Berkeley, CA).

\section{RESULTS}

Aminogram. The aminogram results from the dried blood spots of 36 age-matched control subjects and 20 patients with NICCD are shown in Figure 1. Citrulline, tyrosine, phenylalanine, threonine, and arginine were detected at concentrations of more than $+2 \mathrm{SD}$ of controls. Citrulline concentrations in 19 patients, with the exception of one who was negative on NMS (Fig. 2) were increased to more than $+2 \mathrm{SD}$ of controls (Fig. $3 A$ ). On the other hand, there were few patients with more than +2 SD elevations in tyrosine, phenylalanine, and methionine in comparison with the number of patients with high concentration of citrulline. Elevated levels (more than $+2 \mathrm{SD}$ of controls) of tyrosine, phenylalanine, and methionine were found in 14 of 20 (positive 7/9, negative 7/11), 12 of 20 (positive $7 / 9$, negative 5/11), and 5 of 20 (positive 5/9) patients, respectively.

As shown in Figure 2, one patient, who did not exhibit more than +2 SD of citrulline compared with the control, had low concentrations of all amino acids except for citrulline and tyrosine. To detect relatively high levels of citrulline, the low level of total amino acids must be taken into consideration. As shown in Figure 3B, the mean total level of all 20 amino acids 


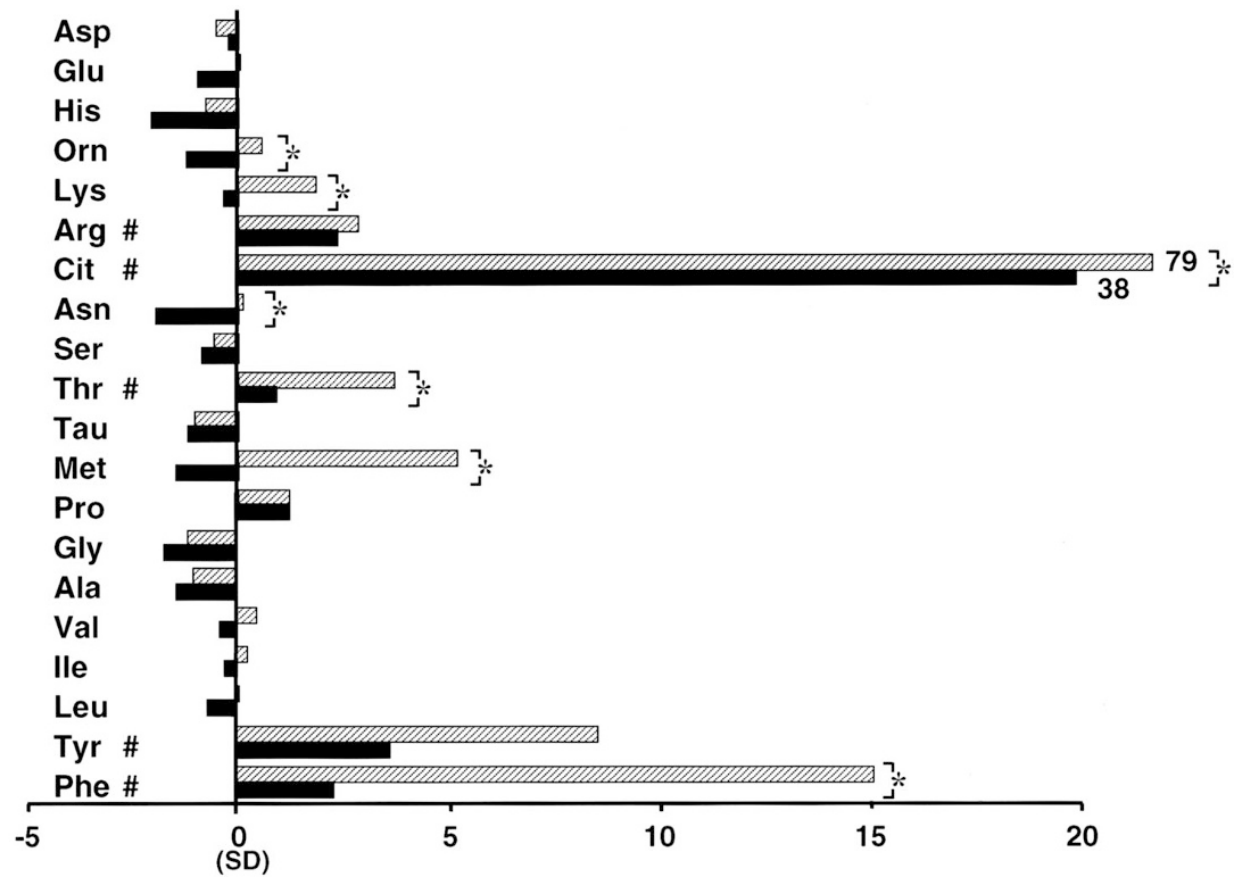

Figure 1. Aminogram of dried blood spots on NMS of 20 patients with NICCD. The zero and numbers indicate the average and SD of age-matched controls $(n=36)$. Hatched bars: positive patients; solid bars: negative patients in NMS. ${ }^{*} p<0.05$, between positives and negatives on NMS. ${ }^{\#}$ The value is more than $+2 \mathrm{SD}$ of controls.



Figure 2. Aminogram of dried blood spots from one NICCD patient with normal citrulline level. The zero and numbers indicate the average and SD values of 36 age-matched controls.

in patients positive on NMS $(3889 \mu \mathrm{M})$ was similar to that of controls $(3856 \mu \mathrm{M})$. On the other hand, patients negative on NMS had a significantly lower $(2788 \mu \mathrm{M})$ total amino acid level. Thus, we examined the ratio of citrulline to total amino acids to exclude the effect of the amount of total amino acids, and all patients showed more than +3 SD of controls (Fig. 3C). As shown in Figure 1, ornithine, lysine, citrulline, asparagine, threonine, methionine, and phenylalanine concentrations in patients positive on NMS were significantly higher than in patients negative on NMS. Leucine plus isoleucine and serine were not affected by NICCD and were selected instead of decreased total amino acids. The ratio of citrulline to serine and citrulline to leucine plus isoleucine in patients with NICCD was more than $+2 \mathrm{SD}$ of controls (Fig. 3, $D$ and $E$ ).

Galactose. The mean galactose-1-phosphate plus galactose of 20 patients with NICCD was $0.61 \pm 0.78 \mathrm{mM}$ and the levels of 13 of 20 patients were above the cut-off value $(0.39 \mathrm{mM}$ in our screening center). This result was different in that 7 of 20 patients were positive for galactose on NMS, because the measurement methods and cut-off values of galactose were different in each mass-screening center. There was no significant difference between galactose-1-phosphate plus galactose values in the positive $(0.87 \pm 1.11 \mathrm{mM})$ and negative patients $(0.38 \pm 0.18 \mathrm{mM})$ on NMS (Fig. $3 F)$.

Bile acids. The mean bile acid concentration in dried blood spots of 20 patients with NICCD was $37.4 \pm 24.6 \mu \mathrm{M}$, which was significantly higher than the age-matched control (12.3 \pm $17.4 \mu \mathrm{M}, n=80$ ). Bile acid concentration in 10 of 20 patients distributed more than $+2 \mathrm{SD}$ of controls. The mean bile acid concentrations in the 9 positive patients $(48.8 \pm 31.3 \mu \mathrm{M})$ and 11 negative patients $(29.2 \pm 15.0 \mu \mathrm{M})$ on NMS were not significantly different (Fig. $3 G$ ).

Changes in amino acids, galactose, and bile acids. We investigated the amino acids, galactose, and bile acid concentrations on d 5 after birth and at 1 mo of age in dried blood spots of eight patients (six were positive on NMS). As shown in Figure 4, galactose increased significantly from $0.24 \pm 0.16$ $\mathrm{mM}$ on $\mathrm{d} 5$ to $2.5 \pm 2.1 \mathrm{mM}$ at $1 \mathrm{mo}$, and bile acids also increased significantly from $49.2 \pm 26.0 \mu \mathrm{M}$ on d 5 to $195 \pm$ $101 \mu \mathrm{M}$ at $1 \mathrm{mo}$. On the other hand, citrulline concentration 


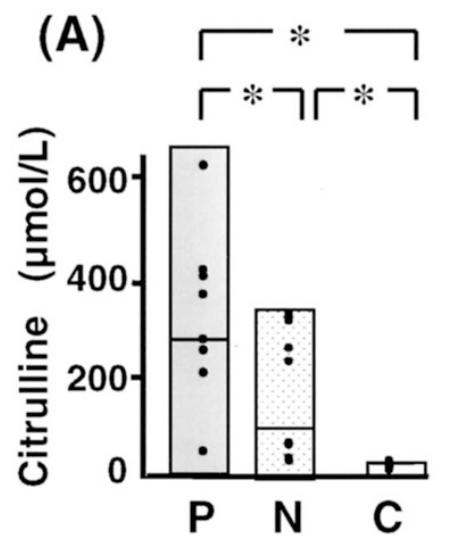

(B)

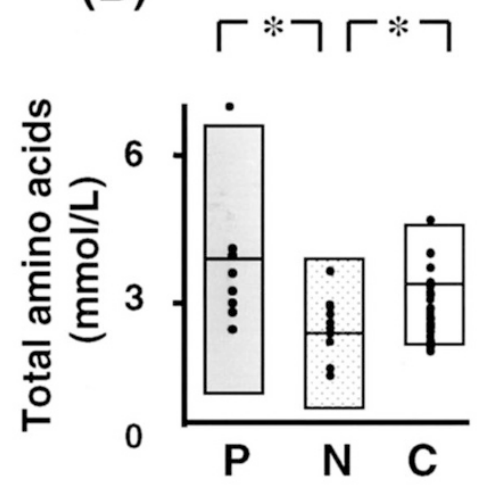

(C)

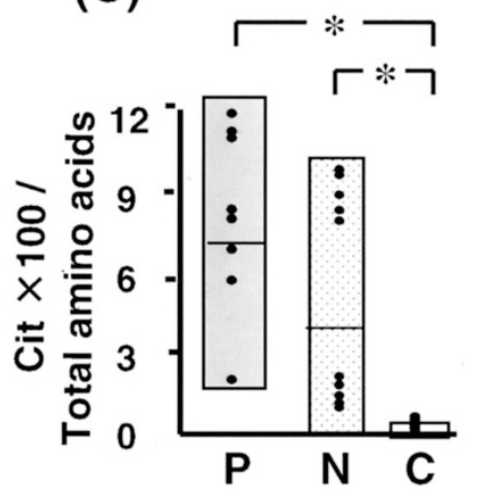

(D)

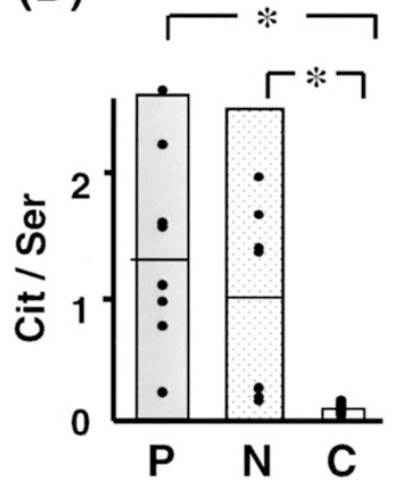

(E)

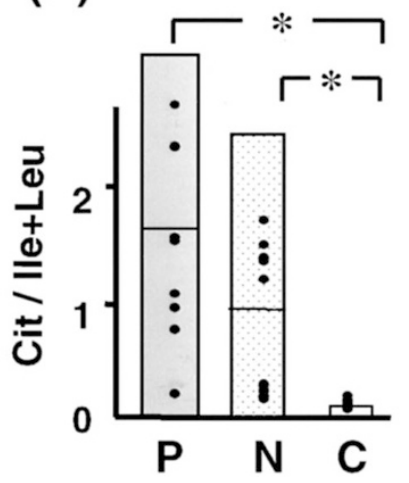

(F)

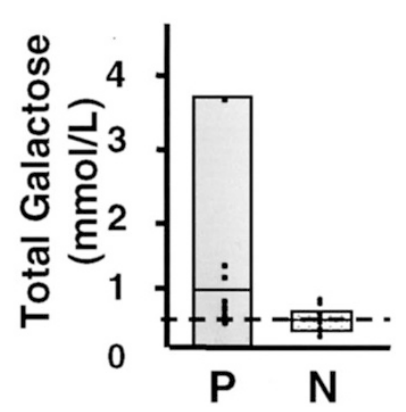

(G)



Figure 3. Comparison and distribution of citrulline, total amino acids, citrulline $\times 100 /$ total amino acids, citrulline/serine, citrulline/leucine plus isoleucine, galactose, and bile acids between positive and negative patients on NMS. Controls are 36 aged-matched normal individuals for amino acids analysis and 80 age-matched normal individuals for bile acids. Horizontal solid bars indicate the mean values. Horizontal broken bar in total galactose indicates the cut-off value of galactose + galactose-1-phosphate for NMS in our institution. Bars represent the mean \pm 2 SD. $P$, positive on NMS $(n=9) ; N$, negative on NMS $(n=11)$; $C$, control $* p<0.05$.

was already elevated on $\mathrm{d} 5$ to $238 \pm 145 \mu \mathrm{M}$ and further increased to $399 \pm 139 \mu \mathrm{M}$ at $1 \mathrm{mo}$.

Mutation types. The results of genetic diagnosis are shown in Table 1. The two mutations of 851del4 and IVS11+ $1 \mathrm{G} \rightarrow \mathrm{A}$ were the most frequently detected in our 20 NICCD patients, as reported previously $(4,5,7,14)$. In the present study, we found 13 alleles in 851 del4 and 15 alleles in IVS11+ $1 \mathrm{G} \rightarrow \mathrm{A}$. The number of cases with 851 del4 mutation was similar in positives (seven alleles) and negatives (six alleles) and there were no significant differences in aminograms, galactose, and bile acids compared with other mutations. The number of cases with IVS11 $+1 \mathrm{G} \rightarrow \mathrm{A}$ mutation was also similar between the positive (seven alleles) and negative (eight alleles) and there were no significant differences compared with other mutations. Each three patients homozygote for 851 del 4 and homozygote for IVS11 $+1 \mathrm{G} \rightarrow \mathrm{A}$ showed both phenotypes of positive or negative on NMS. Concerning the sibling patients homozygote for S225X, the elder brother was positive on NMS whereas the younger sister was negative. Based on these results, we conclude that differences in SLC25A13 genotypes do not seem to affect the positive or negative results on NMS and the clinical and biochemical phenotypes at 4-6 d after birth.

\section{DISCUSSION}

Citrin is an aspartate glutamate carrier protein of the mitochondrial inner membrane expressed in the liver, kidney, and heart $(3,6,19,20)$. Its deficiency can disturb the urea synthesis and malate-aspartate NADH shuttle function. This can lead to the following metabolic abnormalities (7): 1) a decrease in the supply of aspartate from the mitochondria to the cytoplasm resulting in reduced ASS activity, leading to an increase in citrulline and an increase in ammonia due to disturbed urea cycle; 2) inhibition of NADH supply to mitochondria reducing the formation of ATP and the supply of energy in the respiratory chains; and 3 ) the increased $\mathrm{NADH} / \mathrm{NAD}^{+}$ratio in cytosol inhibits glycolysis and also gluconeogenesis from reduced substrates such as lactate, glycerol, and sorbitol.

During the intrauterine period, the fetus derives amino acids and glucose from the maternal body via the placenta. However, it is estimated that the formation of NADH in the mitochondria cannot be compensated by supply from the maternal body. The decrease in birth weight to $-1.4 \mathrm{SD}$ observed in our study indicates that the effect of citrin deficiency begins during the intrauterine period. In other mitochondrial diseases such as respiratory chain-enzyme deficiency, intrauterine growth retar- 



Figure 4. Changes in total galactose, bile acids, and citrulline in dried blood spots from eight (six positive, two negative) patients with NICCD on d 5 after birth and at 1 mo of age. Dotted lines represent the normal ranges. Total galactose indicates galactose + galactose-1-phosphate.

dation was a frequent antenatal feature, although a number of metabolic diseases exhibit a symptom-free period $(21,22)$. Since maternal regulation of fetal amino acids and glucose via the placenta ceases immediately after birth, blood citrulline concentrations in neonates with NICCD begin to increase immediately and are already high on $\mathrm{d} 5$ after birth. In addition, significant increases in phenylalanine, tyrosine, arginine, and threonine are observed most frequently on d 5 after birth. As shown in Figure 4, bile acids and galactose, which are parameters of hepatic dysfunction caused by intrahepatic cholestasis $(23,24)$, were markedly higher at 1 mo compared with $\mathrm{d} 5$ after birth. We suspect that citrin deficiency influences the energy supply in mitochondria during the intrauterine period, with a rise in citrulline appearing first after birth, followed by rises in other amino acids, galactose abnormalities, and cholestasis due to hepatic dysfunction.

NMS for galactose, phenylalanine, and methionine was positive in some cases of NICCD and negative in others. Differences were detected between these two groups with respect to the total amount of all 20 amino acids, citrulline, phenylalanine, and methionine, although no significant differences were observed in birth weight, gestational age at birth, male-tofemale ratio, genotype, galactose, and bile acids (Table 1, Figs. 1 and 3). That is, cases with a normal amount of total amino acids had elevated concentrations of phenylalanine and/or methionine, and were positive on NMS, whereas cases with low amounts of total amino acids were negative on NMS. Based on these results, the positive and negative NICCD neonates on NMS were characterized by: 1) lack of a difference in perinatal history, including birth weight; 2) lack of a difference in genotype; and 3) lack of a difference in the proportion of breast-fed infants and bottle-fed infants. However, since we did not collect data on the amount of milk fed, differences in nutrient consumption between the two groups are unknown at this stage.

The natural history of patients with SLC25A13 mutations is not yet fully clear. The mutant homozygotes developed NICCD during the neonatal period and showed subsidence of the condition by 6-12 mo after birth, except in rare cases $(7,12)$. The frequency of homozygotes with SLC25A13 mutations is estimated to be 1 in 19,000 $(7,14)$ in the Japanese adult population. At adulthood, such patients, especially those with disturbances of compensatory mechanisms, develop CTLN2 with various clinical features such as hyperammonemia, hypercitrullinemia, disorientation, convulsion, and manicdepression psychosis. The frequency of patients with CTLN2 in adulthood and adolescence is reported to be 1 in 230,000 (25) or 1 in 100,000 (26), which is rare compared with the frequency of the homozygotes with SLC25A13 mutations. That is, individuals with SLC25A13 mutations do not always develop CTLN2 in adulthood. This implies the existence of factors that suppress the onset of CTLN2 and other factors that promote its onset. CTLN2 is more frequent in males than in females $(7,14)$ and its onset is likely to relate to sex hormones. At present, treatments include arginine therapy (27) and liver transplantation $(28,29)$. It is possible that radical treatment of this condition by using regeneration and gene therapies could be developed in the future.

In view of the relatively high incidence of citrin deficiency $(1 / 20,000)$ in East Asia (14), the development of such methods for treatment and prevention of CTLN2 will not preclude the usefulness of NMS. In the present study, citrulline was identified as the most appropriate indicator for early detection of NICCD on NMS. Blood citrulline concentrations failed to rise to more than +2 SD in only one of the 20 individuals with SLC25A13 mutations. A previous study reported high threonine/serine ratio and low branched chain amino acid levels in CTLN2 (2). Also in this study, serine and leucine plus isoleucine in patients with SLC25A13 were similar or slightly decreased to those in controls, as shown in Figure 1. Therefore, we selected the citrulline/serine ratio, and the citrulline/leucine plus isoleucine ratio to exclude the effect of the amount of total amino acids. All cases with these mutations had increased citrulline/total amino acids ratio, citrulline/serine ratio, and citrulline/leucine plus isoleucine ratio. These findings indicate that checking the ratio of citrulline to serine or leucine plus isoleucine can offset the influence of a reduction in total blood amino acid levels. It has already been reported that quantification of citrulline by electrospray tandem mass spectrometry 
provides a feasible means of NMS (30). We plan to start a pilot study on tandem mass measurement of citrulline, the citrulline/ serine ratio, and the citrulline/leucine plus isoleucine ratio to evaluate its clinical feasibility. Recently, we experienced one patient who had normal citrulline level and high citrulline/ serine ratio in dried blood spots on NMS by tandem mass measurement, and was diagnosed with NICCD by genetic analysis (data not shown).

\section{REFERENCES}

1. Kobayashi K, Iijima M, Yasuda T, Sinasac DS, Yamaguchi N, Tsui LC, Scherer SW, Saheki T 2000 Type II citrullinemia (citrin deficiency): a mysterious disease caused by a defect of calcium-binding mitochondrial carrier protein. In: Pochet R, Donato R, Haiech J, Heizmann C, Gerke V (eds) Calcium: The Molecular Basis of Calcium Action in Biology and Medicine. Kluwer Academic Publishers, New York, pp 565-587

2. Saheki T, Kobayashi K, Miura T, Hashimoto S, Ueno Y, Yamasaki T, Araki H, Nara H, Shiozaki Y, Sameshima Y, Suzuki M, Yamauchi Y, Sakazume Y, Akiyama K, Yamamura Y 1986 Serum amino acid pattern of type II citrullinemic patients and effect of oral administration of citrulline. J Clin Biochem Nutr 1:129-142

3. Kobayashi K, Sinasac DS, Iijima M, Boright AP, Begum L, Lee JR, Yasuda T, Ikeda S, Hirano R, Terazono H, Crackower MA, Kondo I, Tsui LC, Scherer SW, Saheki T 1999 The gene mutated in adult-onset type II citrullinaemia encodes a putative mitochondrial carrier protein. Nat Genet 22:159-163

4. Yasuda T, Yamaguchi N, Kobayashi K, Nishi I, Horinouchi H, Jalil MA, Li MX, Ushikai M, Iijima M, Kondo I, Saheki T 2000 Identification of two novel mutations in the SLC25A13 gene and detection of seven mutations in 102 patients with adult-onset type II citrullinemia. Hum Genet 107:537-545

5. Yamaguchi N, Kobayashi K, Yasuda T, Nishi I, Iijima M, Nakagawa M, Osame M, Kondo I, Saheki T 2002 Screening of SLC25A13 mutations in early and late onset patients with citrin deficiency and in the Japanese population: identification of two novel mutations and establishment of multiple DNA diagnosis method for the nine mutations. Hum Mutat 19:122-130

6. Palmieri L, Pardo B, Lasorsa FM, del Arco A, Kobayashi K, Iijima M, Runswick MJ, Walker JE, Saheki T, Satrustegui J, Palmieri F 2001 Citrin and aralar1 are $\mathrm{Ca}^{2+}$ stimulated aspartate/glutamate transporters in mitochondria. EMBO J 20:5060-5069

7. Saheki T, Kobayashi K 2002 Mitochondrial aspartate glutamate carrier (citrin) deficiency as the cause of adult-onset type II citrullinemia (CTLN2) and idiopathic neonatal hepatitis (NICCD). J Hum Genet 47:333-341

8. Ohura T, Kobayashi K, Tazawa Y, Nishi I, Abukawa D, Sakamoto O, Iinuma K, Saheki T 2001 Neonatal presentation of adult-onset type II citrullinemia. Hum Genet 108:87-90

9. Tazawa Y, Kobayashi K, Ohura T, Abukawa D, Nishinomiya F, Hosoda Y, Yamashita M, Nagata I, Kono Y, Yasuda T, Yamaguchi N, Saheki T 2001 Infantile cholestatic jaundice associated with adult-onset type II citrullinemia. J Pediatr 138:735-740

10. Tomomasa T, Kobayashi K, Kaneko H, Shimura H, Fukusato T, Tabata M, Inoue Y, Ohwada S, Kasahara M, Morishita Y, Kimura M, Saheki T, Morikawa A 2001 Possible clinical and histologic manifestations of adult-onset type II citrullinemia in early infancy. J Pediatr 138:741-743

11. Naito E, Ito M, Matsuura S, Yokota I, Saijo T, Ogawa Y, Kitamura S, Kobayashi K, Saheki Y, Nishimura Y, Sakura N, Kuroda Y 2002 Type II citrullinemia (citrin deficiency) in a neonate with hypergalactosemia detected by mass screening. J Inherit Metab Dis 25:71-76

12. Tamamori A, Okano Y, Ozaki H, Fujimoto A, Kajiwara M, Fukuda K, Kobayashi K, Saheki T, Tagami Y, Yamano T 2002 Neonatal intrahepatic cholestasis caused by citrin deficiency: severe hepatic dysfunction in an infant requiring liver transplantation. Eur J Pediatr 161:609-613

13. Ohura T, Kobayashi K, Abukawa D, Tazawa Y, Aikawa J, Sakamoto O, Saheki T, Iinuma K 2003 A novel inborn error of metabolism detected by elevated methionine and/or galactose in newborn screening: neonatal intrahepatic cholestasis caused by citrin deficiency. Eur J Pediatr 162:317-322

14. Kobayashi K, Lu YB, Li MX, Nishi I, Hsiao KJ, Choeh K, Yang Y, Hwu W-L, Reichardt JK, Palmieri F, Okano Y, Saheki T 2003 Screening of nine SLC25A13 mutations: their frequency in patients with citrin deficiency and high carrier rates in Asian populations. Mol Genet Metab 80:356-359

15. Hwu WL, Kobayashi K, Hu YH, Yamaguchi N, Saheki T, Chou SP, Wang JH 2001 A Chinese adult onset type II citrullinaemia patient with 851del4/1638ins23 mutations in the SLC25A13 gene. J Med Genet 38:E23

16. Yamaguchi A, Tagami Y, Fukushi M, Oda H, Fujita K 1998 Application of high-performance liquid chromatography with AccQ-Tag precolumn derivatization to the screening for inborn errors of metabolism. J Jpn Soc Mass-screening 8:125

17. Yamaguchi A, Fukushi M, Mizushima Y, Shimizu Y, Takasugi N, Arashima S, Ohyanagi K 1989 Microassay for screening newborns for galactosemia with use of a fluorometric microplate reader. Clin Chem 35:1962-1964

18. Fujimoto A, Okano Y, Miyagi T, Isshiki G, Oura T 2000 Quantitative Beutler test for newborn mass screening of galactosemia using a fluorometric microplate reader. Clin Chem 46:806-810

19. del Arco A, Morcillo J, Martinez-Morales JR, Galian C, Martos V, Bovolenta P, Satrustegui J 2002 Expression of the aspartate/glutamate mitochondrial carriers aralar1 and citrin during development and in adult rat tissues. Eur $\mathrm{J}$ Biochem 269:3313-3320

20. Begum L, Jalil MA, Kobayashi K, Iijima M, Li MX, Yasuda T, Horiuchi M, del Arco A, Satrustegui J, Saheki T 2002 Expression of three mitochondrial solute carriers, citrin, aralar1 and ornithine transporter, in relation to urea cycle in mice. Biochim Biophys Acta 1574:283-292

21. von Kleist-Retzow JC, Cormier-Daire V, Viot G, Goldenberg A, Mardach B, Amiel J, Saada P, Dumez Y, Brunelle F, Saudubray JM, Chretien D, Rotig A, Rustin P, Munnich A, De Lonlay P 2003 Antenatal manifestations of mitochondrial respiratory chain deficiency. J Pediatr 143:208-212

22. von Kleist-Retzow JC, Cormier-Daire V, de Lonlay P, Parfait B, Chretien D, Rustin P, Feingold J, Rotig A, Munnich A 1998 A high rate $(20 \%-30 \%)$ of parental consanguinity in cytochrome-oxidase deficiency. Am J Hum Genet 63:428-435

23. Balisteri WF 1985 Neonatal hepatitis. J Pediatr 106:171-184

24. Batres LA, Maller ES 2001 Laboratory assessment of liver function and injury in children. In: Suchy FJ, Sokol RJ, Balistreri WF (eds) Liver Disease in Children, 2nd Ed. Lippincott Williams and Wilkins, Philadelphia, pp 155-169

25. Nagata N, Matsuda I, Oyanagi K 1991 Estimated frequency of urea cycle enzymopathies in Japan. Am J Med Genet 39:228-229

26. Kobayashi K, Shaheen N, Kumashiro R, Tanikawa K, O’Brien WE, Beaudet AL, Saheki T 1993 A search for the primary abnormality in adult-onset type II citrullinemia. Am J Hum Genet 53:1024-1030

27. Imamura Y, Kobayashi K, Shibatou T, Aburada S, Tahara K, Kubozono O, Saheki T 2003 Effectiveness of carbohydrate-restricted diet and arginine granules therapy for adult-onset type II citrullinemia: a case report of siblings showing homozygous SLC25A13 mutation with and without the disease. Hepatol Res 26:68-72

28. Kasahara M, Ohwada S, Takeichi T, Kaneko H, Tomomasa T, Morikawa A, Yonemura K, Asonuma K, Tanaka K, Kobayashi K, Saheki T, Takeyoshi I, Morishita Y 2001 Living-related liver transplantation for type II citrullinemia using a graft from heterozygote donor. Transplantation 71:157-159

29. Ikeda S, Yazaki M, Takei Y, Ikegami T, Hashikura Y, Kawasaki S, Iwai M, Kobayashi K, Saheki T 2001 Type II (adult onset) citrullinaemia: clinical pictures and the therapeutic effect of liver transplantation. J Neurol Neurosurg Psychiatry 71:663670

30. Shigematsu Y, Hirano S, Hata I, Tanaka Y, Sudo M, Sakura N, Tajima T, Yamaguchi S 2002 Newborn mass screening and selective screening using electrospray tandem mass spectrometry in Japan. J Chromatogr B Analyt Technol Biomed Life Sci $776: 39-48$ 